www.jmscr.igmpublication.org

Impact Factor 3.79

Index Copernicus Value: 5.88

ISSN (e)-2347-176x ISSN (p) 2455-0450

crossref DOI: _http://dx.doi.org/10.18535/jmscr/v4i02.47

Journal Of Medical Science And Clinical Research

IGM Publication

An official Publication of IGM Publication

\title{
A Comparative Study of Lung Function Tests in Pregnant and Non-Pregnant Individuals \\ (Original Article)
}

\author{
Authors \\ Dr Jetty Jerusha $^{1}$, Dr K. Harika Priyadarshini ${ }^{2}$, Dr Malleswaramma ${ }^{3}$ \\ Dr N.VijaySam ${ }^{4}$, B.Navya ${ }^{5}$ \\ ${ }^{1,2}$ Assistant Professors, ${ }^{3}$ Head of the Department, ${ }^{4}{ }^{\text {nd }}$ year MBBS Student, Department of Physiology, Guntur \\ Medical College, Guntur, A.P India. \\ ${ }^{5}$ Sr.Officer, Life Science Incubator, IKP, Hyderabad, India \\ Corresponding Author \\ Dr Jetty Jerusha \\ Assistant Professor, Department of Physiology, Guntur Medical College, Guntur, AP \\ Email id: jettyjerusha@gmail.com
}

\begin{abstract}
:
Introduction: Pregnancy isassociated with physiological changes in control of breathing and lung volumes. Aim: The aim of the present study was to describe the pulmonary function tests changes in pregnant and non-pregnant individuals.

Materials and Methods: The study consists of recording pulmonary function tests of four groups of female subjects including pregnant women of various phases of gestational periods that is $12 w k s\left(1^{\text {st }}\right.$ trimester), $24 w k s$ ( $2^{\text {nd }}$ trimester), 36wks ( $3^{\text {rd }}$ trimester) and control group of non-pregnant women. The study was conducted in pregnant and non-pregnant subjects $(n=100)$ aged between 20-35 years, first the respiratory function values were taken in control group and the parameters selected for the study were expiratory reserve volume, tidal volume, vital capacity, residual volume, minute volume, case group involves 75 pregnant individuals of all the three trimesters were randomly selected from the population.

Result: The results showed statistically significant reduction in expiratory reserve volume and residual volume, there was significant increase in tidal volume, vital capacity and minute volume in three different trimesters of pregnancy.

Conclusion: The data revealed that both from the study and the materials collected concerning respiratory physiology and pregnancy suggest that pulmonary function tests changes during healthy pregnancies should be interpreted cautiously in pregnant women with impaired lung functions.

Keywords: Expiratory Reserve Volume (ERV), Residual Volume(RV), Vital Capacity(VC), Minute Volume $(M V)$
\end{abstract}




\section{Introduction}

Pregnancy represents one of the best examples of selective adaptation in terms of respiratory physiology.

As the uterus expands, the antero-posterior and transverse diameters of thorax increase which enlarges the chest wall circumference. A precise knowledge of the pulmonary function tests and the gradual maternal compromises in these parameters, helps to understand and manage the course and the gestational outcome for a safe delivery. Understanding of the maternal pulmonary function adjustment also helps to avoid inappropriate diagnosis and unnecessary intervention. It also forms the essentials for administration of anesthesia in complicated third trimester pregnancy management and caesarean sections ${ }^{(1)}$. Pulmonary function is affected by total respiratory compliance which is decreased at term as a result of a reduction in chest wall compliance. In pregnancy, the hormonal changes along with progressive increase in abdominal volume may have mechanical impact on respiratory function. However, an increased transverse diameter of the chest, resulting from a widened sub costal angle, opposes the effect of the enlarging pregnant uterus and elevated diaphragm, maintaining an altered pulmonary function during pregnancy. Despite the upward displacement of the diaphragm by the gravid uterus, diaphragm excursion actually increases by $2 \mathrm{~cm}$ when compared with the non-pregnant state ${ }^{[2]}$. Increased diaphragmatic excursion and preserved respiratory muscle strength are important adaptations given the increase in tidal volume and minute ventilation that accompanies pregnancy. Improved diaphragm mechanics in pregnancy are explained by an increased area of apposition of the diaphragm to the rib cage ${ }^{[3]}$. The stability of spirometry during pregnancy suggests that there is no significant change in expiratory airflow resistance with pregnancy. Hormone determined changes in smooth muscle tone and elasticity of the connective tissue which occur during pregnancy could possibly alter the mechanical properties of the respiratory system. The increase in progesterone and estrogen associated with pregnancy contribute to vascular and central nervous system changes. The course of pregnancy is accompanied by structural changes to the ribcage and abdominal compartments as a consequence of the hormonal changes and the enlarged uterus. Cardiac output, pulmonary blood flow, and circulating blood volume are increased due to increased metabolic demands. This increase in blood volume without an increase in red cell mass results in a decreased hemoglobin concentration. There is a reduction in plasma oncotic pressure due to both increased blood volume and a decrease in albumin concentration. The combination of increased pulmonary blood flow, increased pulmonary capillary blood volume, and decreased oncotic pressure all promote the formation of edema in the periphery and in the lung. The dramatic physical and hormonal alterations of pregnancy, perhaps the most remarkable aspect of respiratory physiology is the relatively minor impact that pregnancy has on the function of the lung. To be able to accurately identify and diagnose respiratory abnormalities in pregnant patients, the clinician must first understand normal physiologic changes of pregnancy. A progressive reduction in the functional residual capacity and expiratory reserve volume as term approaches. The reduction in the resting lung volume might be expected to be associated with an increase in airway resistance, which is known to be volume dependent ${ }^{(3)}$. This reduction in FRC is in contrast with the preservation of the vital capacity. The preservation of $\mathrm{VC}$ suggests that lung compliance is notgreatly changed. Third, metabolic changes occurring in pregnant women might modify pulmonary mechanics ${ }^{(4)}$.When seeking to describe the natural course of physiological changes in lung function during pregnancy, the study design and choice of statistical methods and tests are of importance ${ }^{(5)}$. Based on these considerations, we endeavored to perform a more extensive study with repeated measures of healthy pregnant women in order to provide pertinent data on the physiological changes in lung function during pregnancy 


\section{Material \& Methods}

The study was conducted on pregnant and nonpregnant individuals $(\mathrm{N}=100)$. The case group includes pregnant women of various phases of gestation periods of $1^{\text {st }}$ trimester (12 weeks), 2nd trimester (24 weeks) and $3^{\text {rd }}$ trimesters and on control group of non-pregnant women of child bearing age (20-35years).The subjects detailed history was taken each subject was medically examined and their past medical history was carefully evaluated solely aimed at excluding those with pulmonary or cardiac diseases or hypertension, smoking individuals were excluded from the study. The criteria for selection of study were uncomplicated pregnant women, physically and mentally capable of adequate co-operation during the performance of the tests and with hemoglobin percent more than $10 \% \mathrm{gm} / \mathrm{dl}$. The study was approved by the institutional ethical committee clearance. Prior to the study each subject was informed in details of its objectives and the aim of the research protocol and methods to be used. Their consent was obtained.

\section{Experimental Protocol}

Computerized data logging spirometer for pulmonary function tests (UNI-EM spirovin 6.24.9lnk). Non-pregnant individuals similar age were taking as control group( $\mathrm{N}=25)$.Pulmonary function tests of pregnant control group were measured using a spirometer. Prior to the testing subjects were encouraged and supervised throughout the test performance of pulmonary function testing (PFT) and each test was performed using the acceptability standards out lined by the American Thoracic Society(ATS). Subjects were educated prior to pulmonary function test measurements and regarding the PFT performance PFT measurements were carried out for 3 times in each subject and there were small variation among 3 measurements the highest level for each test that is ERV,TV, RV, MV,VC were taken as the correct value.

\section{Statistical Methods}

Data were reported as mean and standard deviation (mean \pm SD), mean were compared between two groups by unpaired ' $t$ 'test. A 'p'value of less than 0.05 was considered statistically significant. Descriptive statistical analysis was carried out in the present study. Result on continuous measurements were presented on (Mean \pm SD). Student ' $t$ ' test was used to find the significance of study parameters between two groups.

\section{Results}

According to the present study,as depicted in the table.1, the mean (TV) of $1^{\text {st }}$ trimester pregnancy individuals was higher than control group which was 0.355 , the difference was found to be statistically highly significant. The mean RV of $1^{\text {st }}$ trimester pregnant individuals was 0.992 , which was lower than mean RV of controlled group the difference was found tobe statistically significant. The mean MV was found to be increased in $1^{\text {st }}$ trimester pregnant women compared to controlled group which was statistically not significant. The mean VC of $1^{\text {st }}$ trimester pregnant women decreased compared to controlled group which statistically not significant. The mean ERV of $1^{\text {st }}$ trimester pregnant women was increased compared to controlled group which was also found to be statistically not significant.

\section{TABLE:1}

\begin{tabular}{|l|l|l|l|l|}
\hline $\begin{array}{l}\text { P.F. } \\
\text { T }\end{array}$ & $\begin{array}{l}\text { Non- } \\
\text { pregnant } \\
\text { mean } \pm \text { SD }\end{array}$ & $\begin{array}{l}\text { IstTrimeter } \\
\text { Pregnant } \\
\text { Women }\end{array}$ & $\begin{array}{l}\text { Unpair } \\
\text { ed T- } \\
\text { Value }\end{array}$ & $\mathbf{P}$ \\
\hline $\begin{array}{l}\text { ER } \\
\text { V }\end{array}$ & $0.712 \pm 0.026$ & $0.723 \pm 0.043$ & -1.058 & 0.29 \\
\hline T.V & $0.333 \pm 0.017$ & $0.355 \pm 0.018$ & 4.48 & 0.000 \\
\hline R.V & $1.16 \pm 0.05$ & $0.992 \pm 0.048$ & 12.09 & 0.000 \\
\hline MV & $6.248 \pm 0.193$ & $6.314 \pm 0.202$ & 1.181 & 0.24 \\
\hline V.C & $3.027 \pm 0.101$ & $2.99 \pm 0.099$ & 1.050 & 0.299 \\
\hline
\end{tabular}


As shown in table 2,the mean TV of $2^{\text {nd }}$ trimester pregnancy was higher than the control group which was 0.399, the difference was found to be statistically highly significant. The mean RV of $2^{\text {nd }}$ trimester was lower than the RV of non-pregnant individuals which was found tobe 0.959, the difference has been found to be statistically highly significant. The mean $\mathrm{MV}$ of $2^{\text {nd }}$ trimester was found to be 6.799 , which was higher than the nonpregnant individuals the difference was also found to be statistically highly significant. The mean VC of the $2^{\text {nd }}$ trimester pregnancy women was found to be 2.95,lower compared to the non-pregnant individuals which was statistically significant. The mean ERV of the $2^{\text {nd }}$ trimester pregnant women was found to be lower compared to the non-pregnant which was statistically non-significant.

\section{TABLE:2}

\begin{tabular}{|l|l|l|l|l|}
\hline P.F.T & $\begin{array}{l}\text { Non- } \\
\text { pregnant } \\
\text { mean } \pm \text { SD }\end{array}$ & $\begin{array}{l}\text { 2ndTrimester } \\
\text { Pregnant } \\
\text { Women }\end{array}$ & $\begin{array}{l}\text { T- } \\
\text { Value }\end{array}$ & P \\
\hline ERV & $0.712 \pm 0.002$ & $0.707 \pm 0.023$ & 0.706 & 0.48 \\
\hline T.V & $0.33 \pm 0.017$ & $0.399 \pm 0.019$ & 12.95 & 0.000 \\
\hline R.V & $1.16 \pm 0.05$ & $0.959 \pm 0.046$ & 14.79 & 0.000 \\
\hline MV & $6.248 \pm 0.193$ & $6.799 \pm 0.214$ & 9.56 & 0.000 \\
\hline V.C & $3.027 \pm 0.101$ & $2.95 \pm 0.088$ & 2.550 & 0.014 \\
\hline
\end{tabular}

As shown in the table3, the mean TV of $3^{\text {rd }}$ trimester was found to be increased compared to control group which was 0.469 , the difference was found to be statistically highly significant. The mean RV of $3^{\text {rd }}$ trimester was found to be decreased compared to control group which was 0.860 , the difference was found to be statistically highly significant. The mean $\mathrm{MV}$ of $3^{\text {rd }}$ trimester was found to be increased compared to control group which was 6.810 , the difference was found to be statistically highly significant. The mean VC of $3^{\text {rd }}$ trimester was found to be decreased compared to control group which was 2.888 , the difference was found to be statistically highly significant. The mean ERV of $3^{\text {rd }}$ trimester was found to be decreased compared to control group which was 0.684 , the difference was found to be statistically highly significant.

\section{TABLE:3}

\begin{tabular}{|l|l|l|l|l|}
\hline P.F.T & $\begin{array}{l}\text { Non- } \\
\text { pregnant } \\
\text { mean } \pm \text { SD }\end{array}$ & $\begin{array}{l}\text { 3rd } \\
\text { Trimester } \\
\text { Pregnant } \\
\text { Women }\end{array}$ & $\begin{array}{l}\text { T- } \\
\text { Value }\end{array}$ & P \\
\hline ERV & $0.712 \pm 0.026$ & $0.684 \pm 0.023$ & 4.03 & 0.000 \\
\hline T.V & $0.333 \pm 0.017$ & $0.469 \pm 0.022$ & -24.53 & 0.000 \\
\hline R.V & $1.16 \pm 0.05$ & $0.860 \pm 0.032$ & 25.2 & 0.000 \\
\hline MV & $6.248 \pm 0.193$ & $6.810 \pm 0.226$ & -9.469 & 0.000 \\
\hline V.C & $3.027 \pm 0.101$ & $2.888 \pm 0.085$ & 5.290 & 0.000 \\
\hline
\end{tabular}

\section{Discussion}

In our study the pulmonary para-meters were found to be statistically significant our findings confirmed that increase in TV compared with non-pregnant individuals was highly significant and also decrease RV was highly significant in $1^{\text {st }}$ trimester pregnant women compared with non-pregnant women and found results were coincides the findings of Meredith C,et al (6) Increase in TV, MV and decreased $\mathrm{RV}$ and $\mathrm{VC}$ in $2^{\text {nd }}$ trimester compared to non-pregnant individuals was also statistically significant and our findings are found to be same as that of khemlatatilwaniet al ${ }^{(7)}$. Decrease expiratory ERV, VC, RV and increase TV, MV were found to be highly significant in $3^{\text {rd }}$ trimester compared to non-pregnant individuals and our findings were same as that ofJ. BernardL(8), Robert A,et al(9).

\section{Conclusion}

The present study concluded that pregnancy causes changes in pulmonary function testes. The data revealed both from the study concerning pregnancy suggest distinct pattern of changes. The 
combination of hormonal changes and mechanical effects of enlarging uterus results in significant changes in pulmonary physiology. The enlarging uterus, alter the resting position of diaphragm. It is important for clinician to be aware of the normal physiological changes in pregnancy. Understanding these changes are critical in distinguishing common dyspnea that occurring during pregnancy from path physiological state associated with cardiopulmonary disease seen in pregnancy. The accurate information of the respiratory status of the pregnant individual tothe clinician, obstretianand anesthetistto help in managing respiratory complications of the pregnancy.

\section{Acknowledgements}

Authors would like to thank all the study participants whose cooperation was important for the completion of the study. Authors also thank the Department of Physiology, Guntur Medical College, Guntur for their support throughout the study.

Conflict of interest: None declared

\section{References}

1. Anwar HasanSiddiqui I, NaziaTauheed II, Aquil Ahmad I, ZehraMohsinIII .Pulmonary function in advanced uncomplicated singleton and twin pregnancy, Jornal Brasileiro de Pneumologia ISSN 1806-3713.

2. Dr. Y.Shailaja, Dr.S.Srikanth. Lung function tests in different trimesters of pregnancy, Indian Journal of Basic and Applied Medical Research; December 2013: Vol.-3, Issue-1, P.285-292

3. Dr. PatilHemlata J, Dr. Deokar,Effect of advanced normal pregnancy on pulmonary function tests,International journal of anatomy physiology and biochemistry, IJAPB: Volume: 2; Issue: 1; January 2015 ISSN(Online):2394-3440.

4. TilwaniKhemlata $1 *$ JangidPriya 1, Maheshwari Madhurima 2, TilwaniRk 3, Rajnee 4, Ojha KC, Air Pollution Impacts on Pulmonary Function Test during PregnancyA Review, Scholars Journal of Applied
Medical Sciences (SJAMS), ISSN 2347954X

5. Dr. Lata Gupta, Dr. R. Dixit, Evaluation of pulmonary function tests in normal pregnant (ii \& iii trimester) \&non-pregnant women, iosrJournal of Pharmacy ,e-ISSN: 22503013, p-ISSN: 2319-4219, www.iosrphr.org ,Volume 2 Issue 6 ,Nov-Dec. 2012,PP.29-35

6. 6.Meredith C. McCormack and Robert A. Wise, Respiratory Physiology in Pregnancy, Pulmonary Problems in Pregnancy, Respiratory Medicine,DOI 10.1007/978-159745-445-2_2

7. 7.Khemlatatilwani,Ojha k. C., Binawarab. K., Tilwanir. K.Manojgupta, Pramodnarnoliya, Study of pulmonary function test in females during three different trimester residing in polluted areas of bikaner city in rajasthan, India; International Journal of Basic \& Applied Physiology.

8. 8Bernard L. Gee,t Bernard S. Packer J. Eugene Millen, and E. D. Robin,Pulmonary Mechanics during Pregnancy,Journal of Clinical InvestigationVol. 46, No. 6, 1967

9. 9.Robert A. Wise, Albert J. Polito,Vidya Krishnan, Respiratory Physiologic Changes in Pregnancy,Immunol Allergy Clin N Am 26 (2006) $1-12$. 